\title{
KELAYAKAN KAMPAS REM SEPEDA MOTOR NON ASBESTOS DARI BAHAN AMPAS TEBU (BAGASSE)
}

\author{
Mochammad Fakri Sugianto $^{1)}$, Arlini Dyah Radityaningrum ${ }^{2)}$ \\ ${ }^{1) 2}$ Teknik Lingkungan, Fakultas Teknik Sipil dan Perencanaan, Institut Teknologi Adhi Tama Surabaya \\ email: arlinidr@gmail.com
}

\begin{abstract}
Production of sugar cane results in bagasse waste used as the raw material of animal feed and organic fertilizer. Bagasse contains fiber which is potentially used for raw material of brake lining. The research aimed to determine the best composition of brake lining from non-carbonated bagasse. The research was conducted within a laboratory scaled with the variations of bagasse, aluminum, and brass. The variations of composition were 1) 50\% of bagasse, $25 \%$ of aluminum, $25 \%$ of brass; 2) $40 \%$ of bagasse, $30 \%$ of aluminum, $30 \%$ of brass; 3$)$ 30\% of bagasse, $35 \%$ of aluminum, 35\% of brass. Particle sizes of bagasse fiber used were without sieving; 50 mesh; 100 mesh. The parameter used were worn; Vickers hardness; impact; microscopic image. The best brake lining was the 50 mesh of the first composition on which value of wear, Vickers hardness, and impact, were 1,74 mm; 18,90 HVN dan 0,22 joule/mm respectively.
\end{abstract}

Keywords : aluminum, bagasse, brake lining, brass.

\begin{abstract}
Abstrak
Produksi gula tebu menghasilkan limbah ampas tebu yang dapat digunakan sebagai bahan baku pakan ternak dan pupuk organik. Ampas tebu memiliki kandungan serat, sehingga berpotensi dijadikan bahan alternatif untuk campuran kampas rem kendaraan bermotor non asbestos. Tujuan penelitian adalah untuk menentukan komposisi terbaik kampas rem kendaraan bermotor non asbestos berbahan ampas tebu tanpa karbonisasi. Penelitian ini berskala laboratoratorium, dengan variasi ampas tebu, serbuk alumunium, serbuk kuningan. Variasi komposisi yang digunakan adalah 1) $50 \%$ ampas tebu, $25 \%$ serbuk aluminium, 25\% serbuk kuningan; 2) $40 \%$ ampas tebu, $30 \%$ serbuk aluminium, 30\% serbuk kuningan; 3) 30\% ampas tebu, 35\% serbuk aluminium, 35\% serbuk kuningan. Perbandingan resin epoxy dan hardener yang digunakan pada setiap variasi komposisi adalah 1:1. Ukuran ampas tebu yang digunakan adalah tanpa ayakan, 50 mesh dan 100 mesh. Parameter uji yang digunakan adalah keausan, kekerasan Vickers, impact dan foto mikroskop. Berdasarkan hasil pengujian keausan, kekerasan Vickers dan impact, kampas rem dari bahan ampas tebu non asbestos yang memenuhi standar adalah komposisi 1 dengan ayakan 50 mesh. Komposisi 1 memiliki nilai keausan, nilai kekerasan dan nilai impact adalah 1,74 mm; $18,90 \mathrm{HVN}$ dan 0,22 joule/mm.
\end{abstract}

Keywords: aluminium, ampas tebu, kampas rem, kuningan

\section{PENDAhUluan}

Peningkatan produksi tebu seiring dengan peningkatan limbah tebu yang dihasilkan. Limbah tebu terdiri atas ampas, blotong dan tetes. Limbah berupa ampas tebu, diperkirakan sekitar $90 \%$ dari total limbah tebu (Yudo dan Jatmiko, 2008). Pengolahan limbah ampas tebu kurang efektif dan masih menyebabkan penumpukan limbah yang berpotensi terhadap pencemaran lingkungan.

Ampas tebu sering dimanfaatkan sebagai bahan baku pakan ternak, pupuk organik dan bahan bakar yang bersifat terbatas serta bernilai ekonomis rendah. Sifat ampas tebu adalah berserat, sehingga berpotensi untuk dijadikan bahan alternatif campuran kampas rem (Sugiharto, 2017). 
Kampas rem dari bahan serat ampas tebu dengan karbonisasi menghasilkan nilai kekuatan tarik berkisar antara $1,34 \mathrm{~kg} / \mathrm{mm}^{2}$ $1,63 \mathrm{~kg} / \mathrm{mm}^{2}$ dan nilai kekuatan impak sebesar 88,37 J/m (Yudo dan Jatmiko, 2008). Penelitian yang dilakukan oleh Sugiharto, (2017) menggunakan serat ampas tebu dengan karbonisasi, alumunium dan resin epoxy sebagai campuran kampas rem. Proses pembuatan dilakukan dengan kompaksi pada suhu $150^{\circ} \mathrm{C}$, selama 60 menit. Hasil penelitian menghasilkan nilai gesek untuk uji basah pada ukuran 30 mesh sebesar 32,81 $\mathrm{mm}^{3} / \mathrm{jam}$; ukuran 40 mesh sebesar 28,12 $\mathrm{mm}^{3} / \mathrm{jam}$ dan ukuran 50 mesh 29,68 $\mathrm{mm}^{3} / \mathrm{jam}$. Uji kekerasan Brinnel menghasilkan nilai untuk ukuran 30 mesh 20,376 BHN, ukuran 40 mesh 18,006 BHN dan ukuran 50 mesh 16,496 BHN.

Ampas tebu dapat digunakan sebagai bahan campuran dalam pembuatan kampas rem, baik dengan karbonisasi atau tanpa karbonisasi (Sugiharto, 2017). Tujuan penelitian ini adalah untuk menentukan komposisi terbaik kampas rem kendaraan bermotor non asbestos dari bahan ampas tebu tanpa pengarangan. Penelitian ini menggunakan ampas tebu serta serbuk alumunium, serbuk kuningan dan resin epoxy untuk perekat dan juga pengisi.

\section{METODOLOGI}

Penelitian dilakukan pada skala laboratorium di Laboratorium Kualitas dan Rekayasa Lingkungan, Jurusan Teknik Lingkungan Institut Teknologi Adhi Tama Surabaya (ITATS). Alat yang digunakan dalam penelitian ini adalah timbangan digital dengan spesifikasi I-2000 dan kapasitas 3000 gram $\mathrm{x} 0,1$ gram. Penelitian ini juga menggunakan cetakan spesimen, jangka sorong, amplas grade 120, vakum merk Electrolux. Ampas tebu dihancurkan dengan blender berbahan plastik, dengan merk Miyako BL-101, berukuran 15×24×26, berkapasitas $100-300 \mathrm{ml}$. Ayakan yang digunakan berukuran 50 dan 100 mesh.

Bahan yang digunakan adalah ampas tebu yang tidak dikarbonisasi, dengan variasi ukuran tanpa ayakan, 50 dan 100 mesh; serbuk aluminium; serbuk kuningan; resin epoxy; hardener. Perbandingan resin epoxy dan hardener adalah 1:1. Penelitian ini menggunakan variasi komposisi 1) $50 \%$ ampas tebu, 25\% serbuk aluminium, 25\% serbuk kuningan; 2) 40\% ampas tebu, 30\% serbuk aluminium, $30 \%$ serbuk kuningan; 3 ) $30 \%$ ampas tebu, 35\% serbuk aluminium, $35 \%$ serbuk kuningan.

Bahan ampas tebu dijemur selama 7 hari untuk menghilangkan kadar air, kemudian diblender dan diayak. Pencampuran dengan serbuk aluminium, serbuk kuningan, resin epoxy dan hardener dilakukan setelah pengayakan. Campuran spesimen kemudian dicetak dengan cetakan spesimen kampas rem. Pengujian kualitas kampas rem dilakukan terhadap parameter keausan, kekerasan Vickers, impact dan foto mikroskop. Standar yang digunakan adalah SNI 09-0143-1987 untuk keausan; SNI Indoparts 05-0719-1989 untuk kekerasan Vicker; dan ASTM D 6110-04 untuk impact.

\section{HASIL DAN PEMBAHASAN}

Sifat mekanik bahan merupakan respon bahan terhadap beban yang diberikan (Aminur et al., 2015). Pengujian sifat mekanik dilakukan melalui sifat keausan, kekerasan dan impact (Aminur et al., 2015). Nilai keausan menunjukkan kehilangan berat kampas rem saat terkena abrasi (Purboputro, 2014). Pengujian weight loss dilakukan dengan kecepatan konstan 300 rpm dan waktu yang selama 15 menit. Nilai weight loss spesimen kampas rem non asbestos dari bahan ampas tebu terdapat pada Tabel 1 .

Kampas rem non asbestos dari ampas tebu pada komposisi 1 berukuran 50 mesh memiliki nilai weight loss terendah. Selain itu, komposisi 1 dari tiap variasi ukuran serat ampas tebu dalam spesimen memiliki nilai keausan terendah. Hal ini disebabkan karena persentase serat ampas tebu dalam spesimen komposisi 1 adalah tertinggi dibandingkan dalam komposisi 2 dan 3. Serat sebagai bahan kampas rem berfungsi untuk meningkatkan koefisien gesek dari kampas rem (Purboputro dan Prabowo, 2019). Semakin besar jumlah serat yang digunakan, maka semakin tinggi nilai koefisien gesek kampas rem. Hal ini mengakibatkan kampas rem memiliki nilai keausan yang rendah, 
Mochammad Fakri Sugianto, dan Arlini Dyah Radityaningrum : Kelayakan Kampas Rem Sepeda Motor Non Asbestos Dari Bahan Ampas Tebu (Bagasse)

Tabel 1 Nilai keausan spesimen kampas rem dari bahan ampas tebu

\begin{tabular}{|l|l|l|}
\hline \multicolumn{2}{|c|}{ Jenis kampas rem } & Weight loss (gr) \\
\hline \multicolumn{2}{|c|}{ Asbestos SNI 09-0143-1987 } & 2 \\
\hline \multirow{3}{*}{$\begin{array}{l}\text { Non Asbestos } \\
\text { (ampas tebu) }\end{array}$} & Tanpa ayakan komposisi 1 & 1,87 \\
\cline { 2 - 3 } & Tanpa ayakan komposisi 2 & 2,61 \\
\cline { 2 - 3 } & Tanpa ayakan komposisi 3 & 2,22 \\
\cline { 2 - 3 } & Ayakan 50 mesh komposisi 1 & 1,74 \\
\cline { 2 - 3 } & Ayakan 50 mesh komposisi 2 & 2,71 \\
\cline { 2 - 3 } & Ayakan 50 mesh komposisi 3 & 2,52 \\
\cline { 2 - 3 } & Ayakan 100 mesh komposisi 1 & 2,05 \\
\cline { 2 - 3 } & Ayakan 100 mesh komposisi 2 & 3,06 \\
\cline { 2 - 3 } & Ayakan 100 mesh komposisi 3 & 2,74 \\
\hline
\end{tabular}

Selain nilai keausan, parameter dalam spesimen kampas rem yang diuji adalah nilai kekerasan Vickers. Uji kekerasan merupakan salah satu pengujian merusak yang dilakukan menggunakan identor intan dengan diagonal $136^{\circ}$. Hasil pengujian kekerasan Vickers dtunjukkan pada grafik dalam Gambar 1.

Nilai kekerasan Vickers berdasarkan standar SNI Indoparts 05-0719-1989 adalah sebesar 18,5 HVN. Berdasarkan Gambar 1, spesimen kampas rem dengan ukuran 50 mesh pada setiap komposisi memiliki nilai kekerasan Vickers lebih rendah daripada specimen dengan ukuran 100 mesh pada komposisi yang sama.
Ukuran partikel menentukan nilai kekerasan kampas rem. Semakin kecil ukuran partikel serat komposit penyusun kampas rem, maka rongga dalam kampas rem semakin kecil. Hal ini menyebabkan kampas rem memiliki permukaan lebih rapat (Purboputro dan Prabowo, 2019).

Nilai kekerasan yang digunakan dalam penelitian ini merupakan nilai kekerasan yang paling mendekati dengan nilai kekerasan kampas rem pada standar SNI Indoparts 050719-1989. Spesimen kampas rem dengan nilai kekerasan yang paling mendekati dengan nilai kekerasan kampas rem pada standar SNI Indoparts 05-0719-1989 adalah komposisi 1

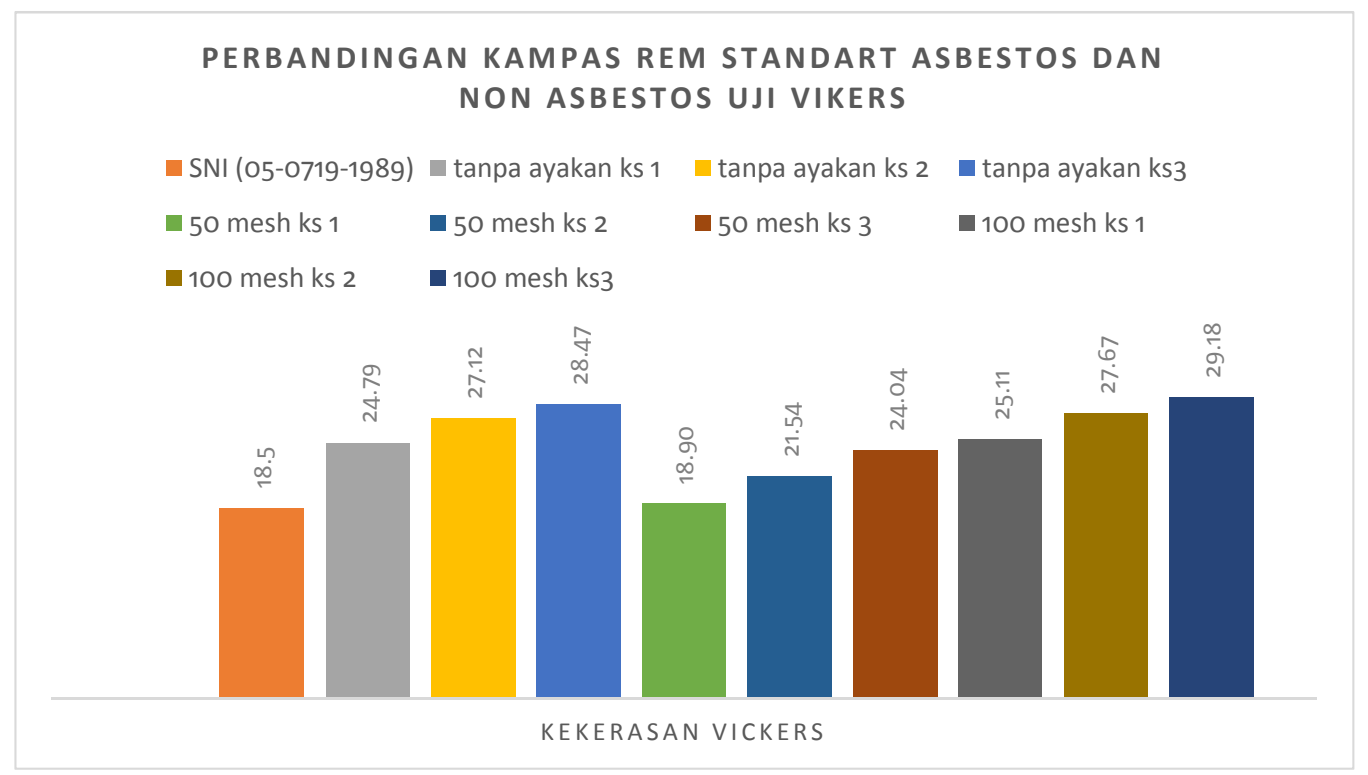

Gambar 2. Perbandingan nilai kekerasan Vickers spesimen kampas rem dari bahan ampas tebu 
ayakan 50 mesh, dengan nilai kekerasan sebesar 18,90 HVN.

Uji impact adalah salah satu cara untuk mengetahui sifat mekanik suatu komposit. Penelitian ini menggunakan standar ASTM D 6110-04 sebagai dasar pengujian impact. Hasil uji impact pada spesimen kampas rem berbahan ampas tebu dapat dilihat dalam Tabel 2.

Berdasarkan Tabel 2, spesimen kampas rem dengan ukuran partikel 100 mesh memiliki nilai mpact tertinggi. Ukuran partikel yang halus dan kecil memiliki potensi untuk terdistribusi merata dalam komposit spesimen kampas rem (Mahayatra et al., 2013). Distribusi partikel berukuran kecil dalam komposit menyebabkan tahanan spesimen kampas rem menjadi kecil, sehingga memiliki nilai impact yang tinggi (Mahayatra et al., 2013).
Hasil penelitian juga menunjukkan bahwa pada komposisi 1 spesimen kampas rem dengan komposisi serat yang paling banyak mampu menghambat patahan atau cracking dengan cepat. Dengan demikian, nilai impact yang dimiliki lebih kecil daripada komposisi dengan persentase serat yang lebih kecil. Pengujian nilai impact menghasilkan bentuk dan jenis patahan komposit dari bahan serat ampas tebu. Foto mikroskopis hasil pengujian impact pada komposisi 1 spesimen kampas rem dapat dilihat dalam Gambar 2.

Tabel 2 Nilai impact spesimen kampas rem dari bahan ampas tebu

\begin{tabular}{|c|c|c|c|c|c|c|}
\hline \multicolumn{2}{|c|}{ Kampas Rem } & A & B & A & $\Delta \mathbf{E}$ & Is \\
\hline $\begin{array}{c}\text { Ukuran } \\
\text { serat ampas }\end{array}$ & $\begin{array}{l}\text { Variasi spesimen } \\
\text { kampas rem }\end{array}$ & {$\left[{ }^{\circ}\right]$} & {$\left[{ }^{\circ}\right]$} & $\mathrm{cxd}$ & Joule & Joule/mm2 \\
\hline & Kontrol Resin & 120 & 89 & 97.5 & 19,95 & 0.20 \\
\hline \multirow{3}{*}{$\begin{array}{l}\text { Tanpa } \\
\text { Ayakan }\end{array}$} & Komposisi 1 & 120 & 84 & 97.5 & 23,15 & 0,24 \\
\hline & Komposisi 2 & 120 & 70 & 97.5 & 32,41 & 0,33 \\
\hline & Komposisi 3 & 120 & 78 & 97.5 & 27,00 & 0,27 \\
\hline \multirow{3}{*}{50 Mesh } & Komposisi 1 & 120 & 86 & 97.5 & 21,95 & 0,23 \\
\hline & Komposisi 2 & 120 & 75 & 97.5 & 28,94 & 0,30 \\
\hline & Komposisi 3 & 120 & 81 & 97.5 & 25,08 & 0,26 \\
\hline \multirow{3}{*}{$100 \mathrm{Mesh}$} & Komposisi 1 & 120 & 80 & 97.5 & 25,85 & 0,27 \\
\hline & Komposisi 2 & 120 & 68 & 97.5 & 33,56 & 0,34 \\
\hline & Komposisi 3 & 120 & 76 & 97.5 & 28,55 & 0,29 \\
\hline
\end{tabular}




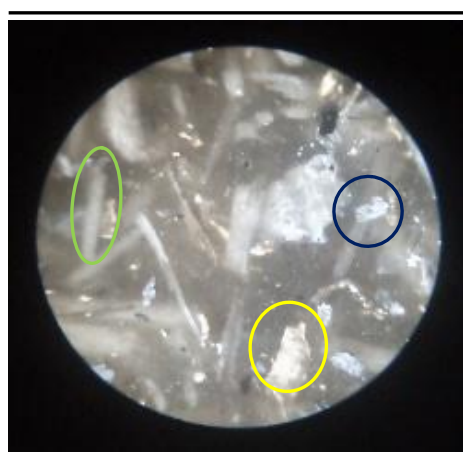

A. Spesimen kampas rem komposisi 1 tanpa ayakan

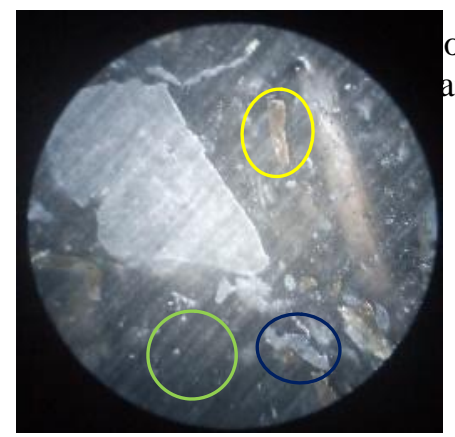

B. Spesimen kampas rem komposisi 1 ukuran 50 mesh

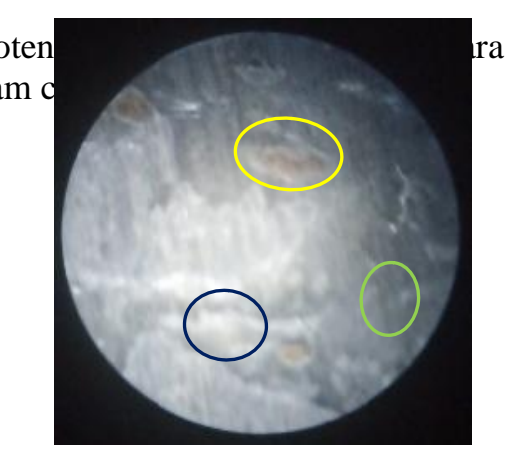

C. Spesimen kampas rem komposisi 1 ukuran 100 mesh

Gambar 2. Foto mikroskopis hasil uji impact spesimen kampas rem dari bahan ampas tebu

Foto mikroskop terhadap hasil uji impact bertujuan untuk mengetahui dan membedakan kerusakan yang terjadi pada spesimen. Selain itu, foto mikroskop dapat digunakan untuk mengetahui distribusi dan ikatan antara masing-masing bahan penyusun kampas rem, yaitu serat ampas tebu, serbuk alumunium, serbuk kuningan dan resin epoxy.

Berdasarkan Gambar 2, spesimen kampas rem komposisi 1, terlihat bahwa ada banyak serat ampas tebu pada semua bagian spesimen. Hal ini disebabkan karena perbandingan komposisi bahan pada spesimen kampas rem komposisi 1 didominasi oleh serat ampas tebu, yaitu sebesar 50\%. Gambar 2.A menunjukkan bahwa terdapat sedikit patahan pada uji impact daripada patahan pada Gambar 2.B dan 2.C. Hal ini diakibatkan pada Gambar 2.A, spesimen kampas rem komposisi 1 terbuat dari bahan serat ampas tebu yang tidak diayak. Partikel serat ampas tebu yang tidak dilakukan pengayakan merupakan partikel memiliki ukuran yang tidak seragam. Selain itu, partikel serat ampas tebu berukuran besar, sehingga mampu menahan terjadnya patahan pada saat uji impact.

Distribusi serat ampas tebu pada Gambar 2.B dan 2.C terlihat lebih merata dibandingkan dengan distribusi serat ampas tebu pada Gambar 2.A. Hal ini terjadi karena bahan serat ampas tebu yang digunakan pada Gambar 2.B dan 2.C berukuran lebih kecil. Menurut Mahayatra et al. (2013), ukuran partikel serat yang lebih kecil, apabila digunakan sebagai bahan campuran kampas

\section{KESIMPULAN}

Dari hasil penelitian yang telah dilakukan, diperoleh kesimpulan sebagai berikut:

1. Berdasarkan hasil pengujian keausan kekerasan Vickers dan impact, kampas rem dari bahan ampas tebu non asbestos yang memenuhi nilai standar adalah spesimen kampas rem komposisi 1, yaitu terdiri dari $50 \%$ ampas tebu, $25 \%$ serbuk kuningan, 25\% serbuk alumunium dan 1:1 resin epoxy dengan ukuran 50 mesh.

2. Nilai keausan, kekerasan Vickers dan impact pada spesimen kampas rem komposisi 1 ukuran 50 mesh, masingmasing adalah $1,74 \mathrm{~mm}, 18,90 \mathrm{HVN}$ dan 0,22 joule $/ \mathrm{mm}$.

\section{UCAPAN TERIMAKASIH}

Ucapan terimakasih disampaikan oleh penulis kepada seluruh dosen di Jurusan Teknik Lingkungan ITATS dan laboran di Laboratorium Kualitas dan Rekayasa Lingkungan, Jurusan Teknik Lingkungan ITATS atas dukungannya dalam pelaksanaan penelitian ini.

\section{REFERENSI}

1. Aminur, Hasbi, M., Gunawan, Y., (2015), Proses Pembuatan Biokomposit Polimer Serat untuk Aplikasi Kampas Rem. Seminar Nasional Sains dan Teknologi, Fakultas Teknik Universitas Muhammadiyah Jakarta.

2. Anonim, (1987), SNI 09-0143-1987 tentang Kampas rem kendaraan bermotor - 
Klasifikasi, keuasan, dimensi dan koefisien gesek, Badan Standarisasi Nasional, Indonesia.

3. Anonim, (1989), SNI 05-0719-1989 tentang Mikro Vickers Beban 0,0098 sampai dengan $49 \mathrm{~N}$, Cara Uji Keras, Badan Standarisasi Nasional, Indonesia.

4. Anonim, Annual Book of ASTM Standards, ASTM D6110-04 "Standard Test Method for Determining The Charpy Impact Resistance of Notched Specimens of Plastics", American Society for Testing and Materials, Philadelphia, .

5. Mahayatra, I. G., Harnowo, S., Savetlana, S., (2013), Pengaruh Variasi Ukuran Partikel Marmer Statuari terhadap Sifat Mekanik Komposit Partikel Marmer Statuari, Jurnal Fema, Vol. 1, No. 4, pp. 13-17.

6. Purboputro, P. I., Prabowo, B. A., (2019) Analisa Pengaruh Serat Rami dan Fiberglass dengan Variasi Butiran Kuningan $(\mathrm{Cu}-\mathrm{Zn})$ Mesh 40, 50, 60 terhadap Nilai Kekerasan, Keausan, dan
Koefisien Gesek Kampas Rem, Media Mesin: Jurnal Ilmiah Teknik Mesin, Vol. 20, No. 2, pp. 32-40.

7. Purboputro, (2014), Pengembangan Ketahanan Keausan pada Bahan Kampas Rem Sepeda Motor dari Komposit Bonggol Jagung, Media Mesin, Vol. 15, No. 1, pp. 41-48.

8. Sugiharto, (2017), Karakterisasi Kampas Rem Tromol Sepeda Motor Berbahan Komposit Serbuk Arang, Kalapa Sawit, Serat Ampas Tebu dan $\mathrm{CaCO}_{3}$ dengan Pengikat Resin Epoxi, Skripsi, Universitas Muria Kudus.

9. Yudo, H., Jatmiko, S., (2008), Analisa Teknis Kekuatan Mekanis Material Komposit Berpenguat Serat Ampas Tebu (Baggase) Ditinjau dari Kekuatan Tarik dan Impak, Kapal, Vol. 5, No. 2, pp. 95101. 